\title{
Hipertrigliseridemiye bağlı akut pankreatitli hastalarımız ve plazmaferez deneyimimiz
}

\author{
Our experience on patients with hypertriglyceridemia-induced acute pancreatitis and plasmapheresis
}

\author{
Muhammet Yener AKPINAR, Erkin ÖZTAŞ, Zeki Mesut Yalın KILIÇ, Mustafa KAPLAN, Volkan GÖKBULUT, \\ Ertuğrul KAYAÇETIN
}

Türkiye Yüksek İhtisas Eğitim ve Araştırma Hastanesi, Gastroenteroloji Kliniği, Ankara

Giriş ve Amaç: Akut pankreatitin \%1-5 nedeni hipertrigliseridemidir. Insülin infüzyonu, heparin infüzyonu ve plazmaferez hipertrigliseridemiye bağlı akut pankreatitin tedavisinde yer almaktadır. Biz bu çalışmamızda hipertrigliseridemiye bağı oluşan akut pankreatitli hastalarımızın demografik özelliklerini, pankreatitlerinin seyrini, uygulanan tedavi yöntemlerini ve plazmaferezin etkinliğini araştırdık. Gereç ve Yöntem: Türkiye Yüksek Ihtisas Hastanesi Gastroenteroloji Kliniği'nde 2012-2016 yılları arasında akut pankreatit tanısı konulan hastalar retrospektif olarak tarandı. Ilk başvuruda trigliserid değeri $900 \mathrm{mg} / \mathrm{dl}$ ve üzeri olan hastalar, diğer etiyolojik nedenlerin yokluğunda hipertrigliseridemiye bağı akut pankreatit olarak kabul edildi. Hastaların medikal bilgilerine hasta dosyaları ve hastane otomasyon bilgi sisteminden ulaşıldı. Bulgular: Toplam 10 hasta (E/K: 4/6, yaş ortalaması 41,4 (26-51) çalışmaya alındı. Hastalarımızda akut pankreatit atak sıklığı 1,4 (1-3) olarak bulundu. Akut pankreatit şiddetini belirlemede BISAP skorlaması kullanıldı. BISAP skoru yüksek olan hastalara plasmaferez uygulandı (4 hasta). Bu hastaların 3 tanesinde psödokist ve walled-off nekroz oluştuğu görüldü. Walled-off nekroz oluşan bir hastaya perkütan drenaj yapıldı. Toplamda hiçbir hastada mortalite izlenmedi. Sonuç: Hipertrigliseridemi, diğer nedenlere kıyasla akut pankreatite nadiren yol açar. Bu hastaların erken tanınması ve uygun tedavisi hastalık ilişkili morbidite ve mortalitenin azalmasına yol açar. Plazmaferez özellikle ciddi seyreden hastalarda etkili bir tedavi yöntemidir.

Anahtar kelimeler: Akut pankreatit, hipertrigliseridemi, plazmaferez

\section{GíRiş}

Akut pankreatit (AP) pankreasın akut inflamatuvar hastalığıdır. Safra taşları ve alkol akut pankreatitin en sık görülen nedenleridir. Bununla beraber ilaçlardan enfeksiyöz nedenlere kadar bir çok farklı ajan da akut pankreatite yol açabilir (1). Hipertrigliseridemi de akut pankreatit etiyolojinde yer alır. Akut pankreatit \%80 olguda kendi kendini sınırlayan hafif veya ödematöz pankreatit olarak izlenirken \%20 olguda pankreasta nekrozun ve lokal komplikasyonların izlendiği ciddi formda izlenir (2). Etiyolojik
Background and Aims: Hypertriglyceridemia is an etiologic cause of acute pancreatitis, with a frequency of $1 \%-5 \%$. Insulin infusion, heparin infusion, and plasmapheresis can be used for the treatment of acute pancreatitis related to hypertriglyceridemia. The aim of our study was to share our experience with the treatment, clinical course, and demographic features of patients with acute pancreatitis related to hypertriglyceridemia and the effectiveness of plasmapheresis. Material and Methods: Patients with acute pancreatitis diagnosed and treated at Türkiye Yüksek Ihtisas Training and Research Hospital during 20142016 were screened. Those who had hypertriglyceridemia with levels $>900 \mathrm{mg} / \mathrm{dl}$ without any potential cause of acute pancreatitis were included in the study as patients with hypertriglyceridemia-induced acute pancreatitis. Medical data were collected from patients' files and the hospital computer automation system. Results: A total of 10 patients [male/female: 4/6, median age: 41.4 (26-51) years] were included in the study. The frequency of acute pancreatitis was 1.4. The Bedside Index of Severity in Acute Pancreatitis scoring system was used to establish the severity of acute pancreatitis. Patients with a high Bedside Index of Severity in Acute Pancreatitis score were treated with plasmapheresis $(n=4)$. In this group, three patients developed walled off necrosis and pseudocysts. Percutaneous drainage was applied in one patient with walled off necrosis. No mortality was observed in our patients. Conclusion: Hypertriglyceridemia is a rare cause of acute pancreatitis. Early diagnosis and appropriate treatment are important in this group for decreasing the disease-related morbidity and mortality. Plasmapheresis is an effective treatment modality, especially in patients with severe hypertriglyceridemia-induced acute pancreatitis.

Key words: Acute pancreatitis, hypertriglyceridemia, plasmapheresis

nedenlerden bağımsız olarak tedavide erken dönemde uygun parenteral hidrasyon esastır. Hipertrigliserideminin tetiklediği akut pankreatitte ise ilave olarak plazmaferez ve/veya heparin tedavisi gibi farklı tedaviler uygulanabilir (3). Biz bu çalışmamızda hipertrigliseridemiye bağlı akut pankreatitli olgularımızı, laboratuvar özelliklerini, klinik seyirlerini ve uygulanılan plazmaferez tedavisinin etkinliğini araştırdık. 


\section{GEREÇ ve YÖNTEM}

Türkiye Yüksek İhtisas Eğitim ve Araştırma Hastanesi Gastroenteroloji servisinde Şubat 2014- Ekim 2016 tarihleri arasında akut pankreatit tanısıyla servise yatan hastalar retrospektif olarak tarandı. Hastanemize ilk başvuru esnasında trigliserid düzeyi 800 mg/dl ve üzeri olan hastalar diğer etiyolojik nedenlerin yokluğunda hipertrigliseridemiye bağlı AP olarak kabul edildi. Bu hastaların yattıkları dönemde aldıkları tedavilere ve klinik seyirlerine hasta dosyaları ve hastane otomasyon sisteminden ulaşıldı. Hastalık şiddetini belirlemede BISAP skorlaması kullanıldı. Plazmaferez alan hastalara bu işlem ASTEC 204 (Fresenius Comp. Tec, Almanya) cihazıyla, hastanın kilosu, hematokrit düzeyi ve parenteral tedaviler dikkate alınarak 2-4 saat arasında değişen sürelerde uygulandı. Plazmaferez işlemi albumin veya plazma eşliğinde yapıldı.

\section{BULGULAR}

Çalışmaya toplamda 10 hasta alındı. Hastaların yaş ortalaması 41,4 olup 4 hasta erkek, 6 hasta ise kadındı. Hastaların 7 tanesi ilk defa hipertrigliseridemiye bağlı AP geçirirken 2 tanesi 2 defa, 1 tanesi ise üç defa AP atağı geçirmişti. Hastaların yarısında vücut kitle indeksi 30 üzerindeydi. Özgeçmişlerinde diyabet 7 hastada izlenirken 5 hastada önceden tanısı konulmuş hiperlipidemi vardı. Hastaların demografik verileri Tablo 1'de özetlenmiştir.

Hastaların hastaneye başvurularında alınan kanların hepsinde ilk biyokimyasal inceleme serum lipemik olduğu için yapılamadı ve ikinci defa hastalardan kan alınması gerekti. Ortalama amilaz 385,9 U/L, ortalama lipaz değeri ise 159,5 U/L olarak ölçüldü. Hastaların lipid profillerine bakıldığı zaman ise ortalama trigliserid düzeyi 1341,8 mg/ dl, total kolesterol düzeyi 553,8 mg/dl, ortalama yüksek yoğunluklu lipoprotein (HDL) düzeyi 143,7 mg/dl olarak ölçüldü. Serum düşük yoğunluklu lipoprotein (LDL) düzeyi ilk başvuruda sadece 4 hastada ölçülebildi ve ortalama LDL düzeyi 100 mg/dl olarak tespit edildi. Hastaların laboratuvar verileri Tablo 2 'de verilmiştir.

Çalışmaya alınan hastaların akut pankreatit ciddiyetini belirlemede yatak başı akut pankreatit şiddet indeksi [BISAP (bed side index for severity of acute pankreatitis)] skorlaması kullanıldı. Bu skorla temel alınarak hastalarımız sıfırdan üçe kadar puanlandı. Ortalama BISAP skoru 1,2 olup sadece bir hasta 3 puan aldı. Tüm hastalara ilk başvurudan itibaren oral alımları kesilerek uygun ve yeterli intravenöz hidrasyon verildi. Bununla beraber hastaların 4 tanesinde plazmaferez uygulandı. Bu hastaların her birine ikişer seans plazmaferez yapıldı. Hiçbir hastada plazmaferez esnasında komplikasyon oluşmadı. Plazmaferez yapılmayan hastaların BISAP skorları 0-2 arasındayken plazmaferez uygulanan hastaların BISAP skoru 1-3 arasında değişmekteydi. Plazmaferez uygulanan hastaların uzun dönemli takiplerinde iki hastada walled-off nekroz (WON) gelişirken bir hastada psödokist oluştuğu görüldü. WON oluşan bir hastada enfeksiyon ortaya çıktığı için perkütan drenaj işlemi yapıldı ve hasta daha sonra taburcu edildi.

Tablo 1. Hastaların demografilk verileri

\begin{tabular}{|l|c|}
\hline Değisskenler & Sayı \\
\hline Yaş & $41,4(24-62)$ \\
\hline Cinsiyet (Erkek/Kadın) & $4 / 6$ \\
\hline Atak sayısı (Ortalama) & $1,4(1-3)$ \\
\hline VKI & \\
$\quad$ Obez (VKI >30) Hasta & 5 \\
\hline Obez olmayan (VKI <30) Hasta & 5 \\
\hline DM Varlığı & 7 \\
\hline Hiperlipidemi (bilinen) & 5 \\
\hline Plevral efüzyon & 5 \\
\hline Pankreatik nekroz & 2 \\
\hline Psödokist/WON & 3 \\
\hline Plazmaferez uygulanan hasta & 4 \\
\hline Plazmaferez sayısı (Ortalama) & 2 \\
\hline BISAP (Ortalama) & $1,2(0-3)$ \\
\hline
\end{tabular}

VKi: Vücut kitle indeksi. DM: Diyabetes mellitus. WON: Walled off nekroz. BISAP: Bed side index for severity of acute pankreatitis.

\section{Tablo 2. Hastaların laboratuvar verileri}

\begin{tabular}{|l|c|}
\hline Laboratuvar Değerleri & Ortalama \\
\hline Glukoz & $164(85-338)$ \\
\hline ALT & $26,7(9-117)$ \\
\hline AST & $56,2(10-285)$ \\
\hline GGT & $87,7(9-544)$ \\
\hline ALP & $67,3(27-86)$ \\
\hline T. bilirubin & $0,92(0,32-3,04)$ \\
\hline D. bilirubin & $0,26(0,1-1,43)$ \\
\hline Amilaz & $385,9(23-1057)$ \\
\hline Lipaz & $159,5(39-3159)$ \\
\hline Trigliserid & $1341,8(920-1911)$ \\
\hline Total kolesterol & $553,8(239-972)$ \\
\hline HDL & $143,7(27-357)$ \\
\hline LDL & $100(18-174)$ \\
\hline CRP & $141,8(9,1-391)$ \\
\hline Sedimentasyon & $92(19-102)$ \\
\hline
\end{tabular}

ALT: Alanin aminotransferaz, AST: Aspartat aminotranferaz, GGT: Gama glutamil transferaz, ALP: Alkalen fosfataz, T. bilirubin: Total bilirubin, D. bilirubin: Direkt bilirubin, HDL: Yüksek yoğunluklu lipoprotein, LDL: Düşük yoğunluklu lipoprotein, CRP: C-reaktif protein. 


\section{TARTIȘMA}

Hipertrigliseridemiye bağlı akut pankreatit sıklığı tüm etiyolojik nedenler içinde \%1-4 sıklıkta izlenir $(4,5)$. Bu hastalarda başvuru şikayeti diğer etiyolojik nedenlere bağlı oluşan akut pankreatitlerdekine benzer şekilde karın ağrısı, bulantı kusma şeklindedir (6). Akut pankreatitle başvuran bir hastanın serumunun lipemik görünümde olması ve/veya amilazın normal olması hipertrigliseridemi şüphesini artırır (7). Hastaların özgeçmişlerinde hiperlipidemi öyküsü olması, sekonder hipertrigliseridemi yapabilen beta-bloker kullanımı, alkol kullanımı gibi özeliklerin olması da AP ile başvuran hastalarda etiyolojik neden olarak hipertrigliseridemiyi akla getirir (8). Fizik muayenede eruptif ksantomlar ve lipemia retinalis trigliserid düzeyi 2000 mg/dl üzerine çıınca ortaya çıkar (9).

Hipertrigliseridemi tedavisinde plazmaferez önemli bir yer tutar. Trigliseridlerin kendisi toksik değildir; bununla beraber ansature yağ asitlerinin kaynağıdır. Ansatüre yağ asitlerinin pankreatik lipazın yardımıyla artmış üretimi pankreatitin daha ciddi seyretmesine yol açabilir (10). Buradan yola çıkarak plazma trigliserdilerinin plazmafe-

\section{KAYNAKLAR}

1. Frossard JL, Steer ML, Pastor CM. Acute pancreatitis. Lancet 2008;371:143-52

2. Hamada S, Masamune A, Kikuta K, et al; Research Committee of Intractable Diseases of the Pancreas. Nationwide epidemiological survey of acute pancreatitis in Japan. Pancreas 2014;43:1244-8.

3. Yeh JH, Chen JH, Chiu HC. Plasmapheresis for hyperlipidemic pancreatitis. J Clin Apher 2003;18:181-5.

4. Henzen C, Rock M, Schnieper C, Heer K. Heparin and insulin in the treatment of acute hypertriglyceridemia-induced pancreatitis. Schweiz Med Wochenschr 1999;129:1242-8.

5. Fortson MR, Freedman SN, Webster PD III. Clinical assessment of hyperlipidemic pancreatitis. Am J Gastroenterol 1995;90:2134-9.

6. Durrington P. Dyslipidaemia. Lancet 2003;362:717-31.

7. Saligram S1, Lo D, Saul M, Yadav D. Analyses of hospital administrative data that use diagnosis codes overestimate the cases of acute pancreatitis. Clin Gastroenterol Hepatol 2012;10:805-11.

8. Van de Wiel A. The effect of alcohol on postprandial and fasting triglycerides. Int J Vasc Med 2012; 2012:862504

9. Valdivielso P, Ramírez-Bueno A, Ewald N. Current knowledge of hypertriglyceridemic pancreatitis. Eur J Intern Med 2014;25:689-94.

10. Click B, Ketchum AM, Turner R, et al. The role of apheresis in hypertriglyceridemia-induced acute pancreatitis: A systematic review. Pancreatology 2015;15:313-20. rezle uzaklaştırılmasının hastalık ciddiyetini azaltacağı ve hastalık seyrine olumlu etki göstereceği kabul edilir. Plazmaferezle trigliserid düzeyi hızlıca düşmektedir $(11,12)$. Amerikan Afarez Cemiyeti hipertrigliseridemiye bağlı AP tedavisinde plazmaferezi kategori III endikasyon olarak kabul eder. Bunun anlamı plazmaferezin etkinliğinin bu hastalarda tam gösterilemediğidir (13). Literatürdeki çalışmalarda plazmaferez uygulan hastalarda laboratuvar iyileşmesinin daha iyi olduğu görülür (14). Bununla beraber plazmaferezin hastalık seyrini iyileştirici ve ciddiyetini azaltıcı etkisi net gösterilememiştir (15). Chen ve arkadaşları ciddi hipertrigliseridemiye bağlı akut pankreatiti olan hastalarda plazmaferez uygulanan ve uygulanmayan hastalarda komplikasyon ve mortalite açısından fark bulmamışlardır (16).

Sonuç olarak hipertrigliseridemiye bağlı akut pankreatiti erken tanımak, bu hastalıkla ilişkili morbidite ve mortaliteyi azaltmak için önemlidir. Plazmaferez bu hastalarda düşük yan etki profili ile güvenle kullanılabilir. Özellikle ciddi seyreden pankreatitlerde plazmaferez pankreatit ciddiyetini azaltabileceği için erken dönemde kullanılmalıdır.

11. Gubensek J, Buturovic-Ponikvar J, Romozi K, Ponikvar R. Factors affecting outcome in acute hypertriglyceridemic pancreatitis treated with plasma exchange: anobservational cohort study. PLoS One 2014;9:e102748.

12. Al-Humoud H, Alhumoud E, Al-Hilali N. Therapeutic plasma exchange for acute hyperlipidemic pancreatitis: a case series. Ther Apher Dial 2008;12:202-4

13. Schwartz J, Winters JL, Padmanabhan A, et al. Guidelines on the use of therapeutic apheresis in clinical practice-evidence-based approach from the writing committee of the American Society for Apheresis: the sixth special issue. J Clin Apher 2013;28:145-284.

14. Mishalov VG, Markulan LY, Matveyev RM, et al. Efficacy and security of a conventional procedure of plasmapheresis in comlpex of treatment of nonbiliary acute pancreatitis in early phase of the disease. Klin Khir 2016;(2):31-3.

15. Scherer J, Singh VP, Pitchumoni CS, Yadav D. Issues in hypertriglyceridemic pancreatitis: an update. J Clin Gastroenterol 2014;48:195-203.

16. Chen JH, Yeh JH, Lai HW, Liao CS. Therapeutic plasma exchange in patients with hyperlipidemic pancreatitis. World J Gastroenterol 2004;10:2272-4. 